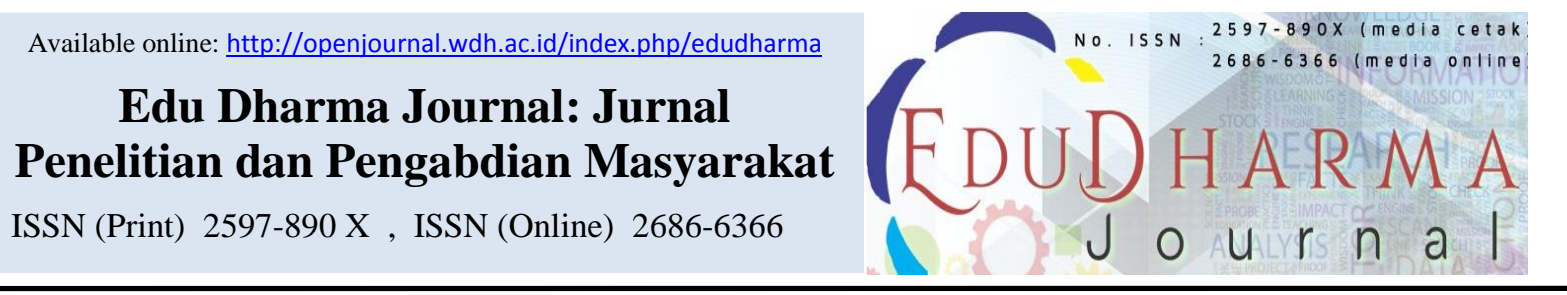

\title{
HUBUNGAN SELF-EFFICACY DENGAN KECEMASAN DALAM PROSES PEMBELAJARAN MAHASISWA SEMESTER II FIKES UNIVERSITAS MUHAMMADIYAH TANGERANG
}

\author{
${ }^{1}$ Een Nuraeni, ${ }^{2}$ Shieva Nur Azizah Akhmad, ${ }^{3}$ Eriyono Budi Wijoyo \\ Universitas Muhammadiyah Tangerang
}

\begin{tabular}{|c|c|}
\hline ARTICLE INFORMATION & $A B S T R A C T$ \\
\hline $\begin{array}{l}\text { *Corresponding Author } \\
\text { Shieva Nur Azizah Akhmad } \\
\text { E-mail: shifa.ahmad14@gmail.com }\end{array}$ & $\begin{array}{l}\text { Online learning causes a lot of conflicts, one of which is anxiety and } \\
\text { makes students' self-efficacy decrease. The age of the second semester } \\
\text { students is still classified as a teenager, therefore they are not } \\
\text { emotionally stable. So that it can be affected by anxiety and self-efficacy. } \\
\text { This study aims to determine the relationship between self-efficacy and }\end{array}$ \\
\hline $\begin{array}{l}\text { Keywords: } \\
\text { Covid-19 pandemic_1 } \\
\text { Online_2 } \\
\text { Student_3 } \\
\text { Self Efficacy_4 } \\
\text { Worry_5 }\end{array}$ & $\begin{array}{l}\text { sample of this study were all students of the second semester of the UMT } \\
\text { nursing study program as many as } 71 \text { respondents. The data analysis } \\
\text { method in this study consisted of univariate analysis to determine the } \\
\text { frequency distribution of each variable. Bivariate analysis was carried } \\
\text { out to analyze the independent variables suspected to have a relationship } \\
\text { with the dependent variable using the Chi Square test (continuity } \\
\text { correction) and the calculation of the Odd Ratio }(O R) \text {. The research } \\
\text { results obtained were yielding (p=0.006) and OR } 0.01 \text {. The conclusion } \\
\text { of this study is that there is a relationship between self-efficacy and } \\
\text { anxiety levels. Suggestions in this study for related parties in learning in } \\
\text { order to modify the systematics in the learning process so that students } \\
\text { do not experience anxiety. }\end{array}$ \\
\hline $\begin{array}{l}\text { Kata Kunci: } \\
\text { Pandemi Covid-19_1 } \\
\text { Daring_2 } \\
\text { Mahasiswa_3 } \\
\text { Self Efficacy_4 } \\
\text { Kecemasan_5 }\end{array}$ & $\begin{array}{l}\text { A B S T R A K } \\
\text { Pembelajaran daring banyak menimbulkan konflik, salah satunya adalah } \\
\text { kecemasan dan menjadikan self efficacy pelajar menurun. Usia } \\
\text { mahasiswa semester II masih tergolong remaja, maka dari itu } \\
\text { emosionalnya belum stabil. Sehingga dapat terpengaruhi kepada } \\
\text { kecemasan dan self efficacynya. Penelitian ini bertujuan mengetahui } \\
\text { hubungan antara self efficacy dengan tingkat kecemasan. Jenis } \\
\text { penelitiain yang digunakan adalah penelitian kuantitatif. Sampel } \\
\text { penelitian ini yaitu semua mahasiswa semestrer II prodi keperawatan } \\
\text { UMT sebanyak } 71 \text { responden. Motode analisis data dalam penelitiain ini } \\
\text { terdiri dari analisis univariat untuk mengetahui distribusi frekuensi dari } \\
\text { masing-masing variable, Analisis bivariat dilakukan untuk menganilisis } \\
\text { variabel independen yang diduga mempunyai hubungan dengan variabel } \\
\text { dependen dengan menggunakan uji Chi Square (continuity correction) } \\
\text { dan perhitungan Odd Ratio (OR). Hasil penelitian yang diperoleh secara } \\
\text { menghasilkan (p=0,006) dan OR 0,01. Kesimpulan penelitian ini yaitu } \\
\text { ada hubungan antara self efficacy dengan tingkat kecemasan. Saran } \\
\text { dalam penelitian ini untuk pihak terkait dalam pembelajaran agar dapat } \\
\text { memodifikasi sistematika dalam proses belajar supaya mahasiswa tidak }\end{array}$ \\
\hline
\end{tabular}


Een Nuraeni_Hubungan Self Efficacy Dengan Kecemasan

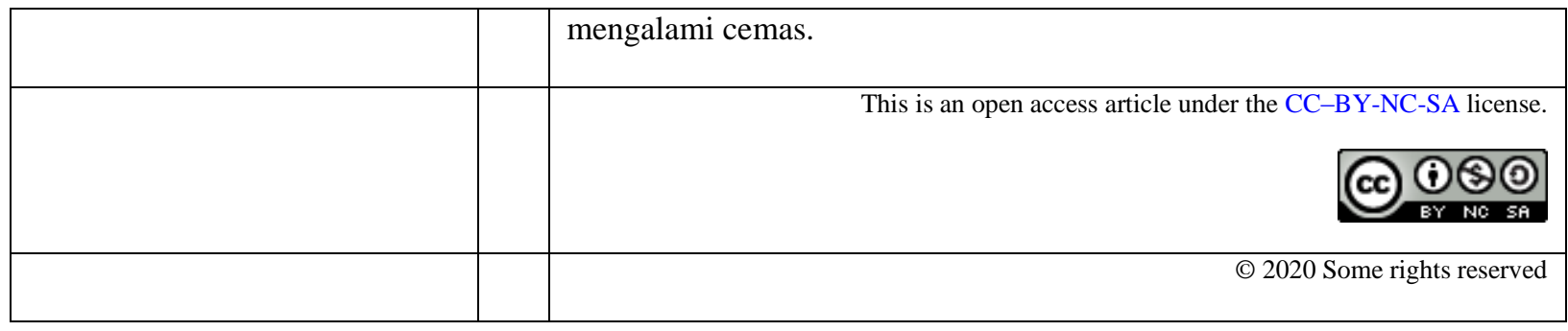




\section{PENDAHULUAN}

Masa pandemi COVID-19 memiliki perhatian dari berbagai Negara di Dunia karena memiliki resiko yang tinggi serta dampak yang sangat besar terkhusus pada Negara yang memiliki sistem Pelayanan Kesehatan yang masih rentan (Halawa, 2020).

Pandemi COVID-19 berpengaruh bagi Dunia Pendidikan. Karena tidak melaksanakan kegiatan tatap muka, tetapi pembelajaran yang dilakukan secara daring atau pembelajaran jarak jauh. Hal ini diharapkan untuk mengurangi penyebaran COVID-19 (Arwani \& ngsih Dwi, 2012). Kemunculan kebijakan tersebut merupakan perubahan awal dalam bidang Pendidikan.

Tercatat dengan prevalensi dari $64,3 \%$ dari 1.522 mahasiswa cemas akibat pandemi ini. Pasien paling banyak berasal dari jawa barat yaitu sebanyak 23,4\%, diikuti oleh DKI Jakarta sebanyak 16,\%, Jawa Tengah 15,55\%, dan Jawa Timur sebanyak 12,8\% (Sunawan et al., 2017).

Menurut Canadian Mental Health Association (2015) menjelaskan bahwa kecemasan merupakan sistem peringatan secara dini untuk bersiap diri terhadap bahaya dan ancaman yang akan datang . Jadi kecemasan adalah emosi yang tidak menyenangkan yang ditandai dengan kekhawatiran, keprihatinan, dan rasa takut. Ada cemas ringan, sedang, berat dan bahkan ada yang sampai terjadi kepanikan.

Kecemasan pada mahasiswa merupakan topik yang sangat penting untuk diperhatikan, karena usia yang paling berpengaruh adalah usia remaja, dan pada usia ini masih terbilang labil, maka hal itu akan menyebabkan masalah besar dalam Psikologi si remaja (Mahfud \& Gumantan, 2020).

Self efficacy merupakan sikap individu mengenai penilaian diri terhadap tindakan yang baik atau buruk, salah atau benar, bisa atau tidak bisa dalam melakukan pekerjaan sesuai dengan yang ditentukan ( Bandura dalam Halawa, 2020).

Self efficacy dibagi menjadi 2 yakni self efficacy tinggi (efikasi positif) dan rendah (efikasi negatif). Pembagian tersebut dapat dipengaruhi oleh seberapa tinggi akan keyakinan individu dalam dirinya untuk mencapai tujuan tertentu (Halawa, 2020).

Berdasarkan uraian diatas peneliti tertarik untuk melakukan penelitian mengenai Hubungan Self-efficacy Dengan Kecemasan Dalam Proses Pembelajaran Mahasiswa Semester II. 


\section{METODE}

Jenis penelitian yang digunakan adalah penelitian kuantitatif dengan desain pendekatan case control. Penelitian dilaksanakan pada Tahun 2021. Populasi merupakan Mahasiswa Semester II dengan jumlah sampel sebanyak 71 responden. Pengambilan sampel dalam penelitian ini menggunakan metode total sampling. Pengumpulan data yang dilakukan dengan menggunakan instrumen kuesioner dengan google form yang dibagikan secara online kepada responden.

\section{HASIL}

Tabel 1. Distribusi Frekuensi Jenis Kelamin Responden Mahasiswa Semester II FIKes UMT Tahun 2021 $(\mathrm{n}=71)$

\begin{tabular}{lcc}
\hline $\begin{array}{c}\text { Jenis } \\
\text { Kelamin }\end{array}$ & Jumlah & $\begin{array}{c}\text { Presentase } \\
(\%)\end{array}$ \\
\hline Laki-laki & 12 & 16,9 \\
Perempuan & 59 & 83,09 \\
\hline \multicolumn{1}{c}{ TOTAL } & 71 & 100
\end{tabular}

Sumber : IBM SPSS

Tabel 1. menunjukkan karakteristik responden mahasiswa semester II FIKes UMT berdasarkan jenis kelamin mayoritas responden berjenis kelamin perempuan yaitu sebanyak 59 responden $(83,098 \%)$.
Tabel 2. Distribusi Frekuensi Usia Responden Mahasiswa Semester II FIKes UMT Tahun 2021 $(\mathrm{n}=71)$

\begin{tabular}{ccc}
\hline Usia & Jumlah & $\begin{array}{c}\text { Presentase } \\
(\mathbf{\%})\end{array}$ \\
\hline 17 Tahun & 2 & 2,8 \\
18 Tahun & 26 & 36,61 \\
19 Tahun & 6 & 8,5 \\
20 Tahun & 2 & 2,8 \\
21 Tahun & 19 & 26,8 \\
22 Tahun & 16 & 22,53 \\
\hline TOTAL & 71 & 100 \\
\hline Sumber: IBM SPSS & &
\end{tabular}

Tabel 2. menunjukan responden responden mahasiswa semester II FIKes UMT berdasarkan usia mayoritas responden dalam usia 18 tahun yaitu sebanyak 26 orang $(36,61 \%)$.

Analisis tabel 3. di atas tentang hubungan self-efficacy dengan tingkat kecemasan pada mahasiswa semester II FIKes UMT yang mengalami selfefficacy rendah dan tinggi dengan tingkat kecemasan rendah tidak ada 0 $(0 \%)$. Kemudian, untuk responden yang mengalami self-efficacy rendah dengan tingkat kecemasan sedang sebanyak 1 orang $(1,4 \%)$, kemudian, responden yang mengalami selfefficacy tinggi dengan tingkat kecemasan sedang tidak ada 0 $(0 \%)$.Untuk responden yang mengalami self-efficacy rendah dengan tingkat kecemasan berat berat terdapat 29 orang $(40,8 \%)$, lalu untuk responden yang mengalami self-efficacy tinggi 
dengan tingkat kecemasan berat pun tidak ada $0(0 \%)$. Lalu, responden yang mengalami self-efficacy rendah dengan tingkat kecemasan kepanikan terdapat
41 orang $(57,7 \%), \quad$ sedangkan responden yang mengalami selfefficacy tinggi dengan tingkat kecemasan kepanikan tidak ada $0(0 \%)$.

Tabel 3. Analisis Chi Square antara Self-Efficacy dengan Kecemasan pada mahasiswa semester II FIKes UMT Tahun $2021(\mathrm{n}=71)$

\begin{tabular}{|c|c|c|c|c|c|c|}
\hline Self-Efficacy & & \multicolumn{3}{|c|}{ Tingkat Kecemasan } & OR & $\mathrm{P}$ value \\
\hline & Rendah & Sedang & Berat & Kepanikan & 0,01 & 0,006 \\
\hline Rendah & $0(0 \%)$ & $1(1,4 \%)$ & $29(40,8 \%)$ & $41(57,7 \%)$ & & \\
\hline Tinggi & $0(0 \%)$ & $0(0 \%)$ & $0(0 \%)$ & $0(0 \%)$ & & \\
\hline TOTAL & $\begin{array}{c}0 \\
(0 \%)\end{array}$ & $\begin{array}{c}1 \\
(1,4 \%)\end{array}$ & $\begin{array}{c}29 \\
(40,8 \%)\end{array}$ & $\begin{array}{c}41 \\
(57,7 \%)\end{array}$ & $71(100 \%)$ & \\
\hline
\end{tabular}

\section{PEMBAHASAN}

Hasil penelitian menunjukkan bahwa dari 71 responden lebih banyak responden yang mengalami kecemasan dan selfefficacy rendah adalah perempuan $(83,09 \%)$ dari pada laki-laki $(16,9 \%)$. Hal ini sejalan dengan penelitian samsugito dan satria (2016), pada penelitiannya mengatakan bahwa mahasiswa perempuan lebih banyak mengalami kecemasan dibandingkan mahasiswa lakilaki. Karena pada aspek somatik, emosional, kognitif, dan tingkah laku laki-laki dengan perempuan sangat berbeda (Maharani et al., 2018)maha.

Dari hasil penelitian menunjukkan bahwa dari 71 responden lebih banyak responden yang mengalami kecemasan dan selfefficacynya rendah adalah pada usia remaja, yaitu usia 18 tahun. Dari rentang usia 17-22 tahun, usia 18 tahun lah yang banyak mengalami kecemasan dan self-

efficacynya rendah dengan jumlah 26 mahasiswa $(36,61 \%)$. Hal ini diperkuat oleh hasil riset sebelumnya yang mengatakan bahwa usia remaja sangat rentan mengalami mood yang berubahubah dengan cepat sehingga dapat mengalami kecemasan berat pada usia remaja (Maharani et al., 2018).

Hasil penelitian ini menunjukkan bahwa dari 71 responden lebih banyak responden yang mengalami self-efficacy rendah sebanyak 71 orang (100\%), sedangkan responden yang mengalami self-efficacy tinggi tidak ada (0\%). Hal ini sejalan dengan hasil riset Priyanti (2021) yang mengatakan bahwa self-efficacy tinggi hanya memiliki kontribusi 46,6\%. Jadi, 
self-efficacy rendah lebih banyak daripada self-efficacy tinggi (Priyanti \& Fauzi, 2021).

Adapun untuk tingkat kecemasan lebih banyak responden yang memiliki tingkat kecemasan berat sekali (kepanikan) sebanyak 41 orang $(57,7 \%)$, kemudian diikuti dengan responden yang memiliki tingkat kecemasan berat sebanyak 29 orang $(40,8 \%)$, lalu untuk responden yang memiliki tingkat kecemasan sedang sebanyak 1 orang $(1,4 \%)$, sedangkan responden yang memiliki tingkat kecemasan rendah tidak ada yang mengalami (0\%). Hal ini karena koefesien korelasi yang ditemukan sangat kuat pada kepanikan mahasiswa dalam pembelajaran daring di masa pandemi covid-19 (Hasanah et al., 2020).

Hasil uji statistik Chi Square pada penelitian ini menunjukkan nilai $\mathrm{p}$ value $=0,006$ yang berarti $\mathrm{p}$ value $<\alpha$ $(0,005)$, sehingga Ho ditolak dan $\mathrm{Ha}$ diterima bahwa terdapat hubungan antara self-efficacy dengan tingkat kecemasan pada mahasiswa semester II Prodi Ilmu Keperawatan UMT. Hasil penelitian tersebut diperkuat dengan hasil riset terahulu yang mengatakan Terdapat hubungan self efficacy terhadap kecemasan siswa (Hasanah, 2020). Selain itu, penelitian ini dengan populasi mahasiswa semester II (Tingkat Pertama) juga didukung oleh hasil penelitian terdahulu yang mengatakan bahwa terdapat hubungan self-efficacy terhadap tingkat kecemasan mahasiswa tingkat pertama (Saba et al., 2018).

\section{KESIMPULAN}

Berdasarkan hasil penelitian dan pembahasan menggunakan uji statistik Chi Square dengan menggunakan program computer IBM SPSS Statistics mengenai Hubungan Self-efficacy dengan Tingkat Kecemasan pada Mahasiswa Semester II UMT Tahun 2021, dapat disimpulkan sebagai berikut:

a. Mahasiswa Semester II UMT memiliki Self-efficacy rendah

b. Mahasiswa Semester II UMT mengalami tingkat kecemasan berat sekali (kepanikan).

c. Terdapat hubungan antara Selfefficacy dengan Tingkat Kecemasan pada Mahasiswa Semester II UMT Tahun 2021 dengan $\mathrm{p}$ value 0,006 dimana nilai $p$ value $<\alpha(0,05)$. 


\section{SARAN}

Perlu ada penelitian lebih lanjut terkait dengan faktor-faktor yang mempengaruhi self-efficacy terutama pada mahasiswa.

\section{DAFTAR PUSTAKA}

Arwani, R., \& Ningsih Dwi, M. (2012). Hubungan Antara Tingkat Pendidikan , Pengetahuan , Sikap Dengan Bancak Kabupaten Semarang Relationship Between the Level of Education , Knowledge , Attitude With Mother Behavior of Children in Disease Prevention of Diarrhea in Health District Bancak. J.Ilmu Dan Tek. Kesehatan, 3, 2336.

Halawa, A. (2020). Self - Efficacy Mahasiswa Dalam Belajar Pada Masa Pandemi Covid-19 Di Stikes William Booth. Jurnal Keperawatan, 9(2), 26-32. https://doi.org/10.47560/kep.v9i2.26 2

Hasanah, N., \& Efficacy, S. (2020). hitung > tabel. 9(2), 54-60.

Hasanah, U., Ludiana, Immawati, \& PH, L. (2020). Gambaran Psikologis Mahasiswa Dalam Proses Pembelajaran Selama Pandemi Covid-19. Jurnal Keperawatan Jiwa, 8(3), 299-306. https://jurnal.unimus.ac.id/index.php /JKJ/article/view/5941

Maharani, M., Supriadi, N., \& Widyastuti, R. (2018). Media Pembelajaran Matematika Berbasis Kartun untuk Menurunkan Kecemasan Siswa. 1(1), 101-106.

Mahfud, I., \& Gumantan, A. (2020). Survey Of Student Anxiety Levels During The Covid-19 Pandemic. Jp.Jok (Jurnal Pendidikan Jasmani,
Olahraga Dan Kesehatan), 4(1), 8697.

https://doi.org/10.33503/jp.jok.v4i1. 1103

Priyanti, S. Y., \& Fauzi, A. (2021). Edukatif: Jurnal Ilmu Pendidikan Analisis Kecemasan Akademis Melalui Self Efficacy dan Dukungan Sosial pada Siswa SMK Jurusan Akuntansi. 3(3), 758-769.

Saba, R. T., Lisiswanti, R., B, E. C.,. (2018). Hubungan Self-efficacy Terhadap Tingkat Kecemasan Mahasiswa Tingkat Pertama Fakultas Kedokteran Universitas Lampung The Relation of Selfefficacy to Level of Anxiety On The First Grade Students of Faculty of Medicine University of Lampung. 7, 12-16.

Sunawan, S., Ahmad Yani, S. Y., Anna, C. T., Kencana, T. I., Mulawarman, , \& Sofyan, A. (2017). Dampak Efikasi Diri terhadap Beban Kognitif dalam Pembelajaran Matematika dengan Emosi Akademik sebagai Mediator. Jurnal Psikologi, 44(1), 28.

https://doi.org/10.22146/jpsi.22742 